\title{
"We could kid on that this is going to benefit the kids but no, this is about funding": cutbacks in services to disabled children and young people in Scotland
}

\begin{abstract}
This paper presents research, commissioned by Scotland's Commissioner for Children and Young People, examining changes in the availability and accessibility of publicly funded services to disabled children, young people and their families between 2011-2013. Methods included a survey of voluntary sector providers and focus groups with family carers and (separately) young disabled people. After outlining the wider context of the economic recession, subsequent reductions in public expenditure in the UK and the move towards neo-liberalism in social work, the paper focuses mainly on family carers' views, with some reference also made to the views of voluntary providers. Carers reported widespread reductions in both the level and quality of services they received from social work, education, the voluntary sector, health and professions allied to medicine, with some children not getting support they had been assessed as needing. There was a move from preventative to crisis work, although some families who appeared to be at 'tipping point' were not receiving the help they needed. Tightened eligibility criteria, a rise in unmet need and long waiting lists were also evident. The impact of the cutbacks on families is discussed. It is argued that disabled children's rights under international conventions, UK and Scots law are at risk of being undermined. The paper concludes by discussing the implications of the findings for policy and practice.
\end{abstract}

\section{Introduction}

The global economic recession which started in 2008 is the most severe since the Great Depression of the 1930s (Dezhao, undated). A key response adopted by many governments, albeit to differing degrees, has been to reduce public expenditure, with both welfare benefits and public services becoming major targets of such change. According to Taylor-Gooby \& Stoker (2011, p.4), in Britain 'the most striking element in the reforms is a cumulative, abrupt and substantial programme of public spending cuts and tax increases.' Writing in 2013, Duffy noted that the current Coalition Government in Britain aims to reduce public expenditure by £63.4 billion by 2015, effectively turning its back on commitments made by its New Labour predecessor to bring the level of public service provision near to that within leading European countries. UK Government strategy involves a far-reaching restructuring of public services, with responsibilities of the central state increasingly shifting to the private sector or, where they remain within the public realm, being devolved to local level in terms of decision-making, budgeting and provision (Taylor-Gooby and Stoker, 2011).

Elder-Woodward (2013a) identifies three ways in which societies can choose to respond to disadvantage. They can promote a libertarian, free-market economy 
involving minimal taxation and the provision of only emergency and security services: those who cannot fend for themselves are expected to rely on charity. Alternatively, societies can adopt Rawls' (1970) Second Principle of Distributive Justice which allows social and economic inequalities to exist so long as there are some benefits for the poorest. Thirdly, communitarian theories promote the idea of citizens joining together in solidarity, offering support to others on the grounds of their shared humanity rather than 'banking' one good turn now in the expectation that it will be returned later. Elder-Woodward (2013a: 274) argues that the UK currently adopts a utilitarian stance associated with the second approach, promoting 'the greatest good for the greatest number', leaving little room for unsupported minorities to flourish. Welfare is distributed not only according to individual need but also to individuals' or groups' perceived value. Taylor-Gooby \& Stoker (2011:11) broadly concur, concluding that the UK has moved to a position of 'inegalitarian liberalism.'

This position is reflected in the recent growth in neo-liberalism and managerialism in some strains of social work ideology, policy and practice at both European level (Harlow et al., 2012; Diamond \& Lodge, 2013) and within the UK (Ferguson \& Woodward, 2009). The 'best value' approach highlighted in the English White Paper Modernising Local Government, (DETR, 1998) promotes economy, efficiency, effectiveness and quality in public services. In Scotland, best value aims to shift the focus of public services from provider to customer 'by delivering services people want to a quality they want and at a cost they can afford' (Scottish Office, 1998: 38). Some commentators see this as 'not dissonant' with social work values (e.g.: Fletcher 2000: 29) although challenging to implement within social work practice due to the latter having a poor public image, vulnerable service users with little political leverage, and complex services and structures which are difficult to evaluate. Ferguson \& Woodward (2009) go further, arguing that 'best value' is part of the marketisation of care, undermining traditional social work principles and devaluing the professional social work role, resulting in a loss of autonomy for staff. The shift towards care management, for example, involving an increase in bureaucracy and a division between the provision and purchasing of support, has led to a fragmentation of day-to-day tasks, leaving social workers little time for direct work with service users

Alongside these changes has come an increase in demand for social work services, including children's and family services. The recession is one significant underlying factor, with rising numbers of people losing their jobs, sometimes compounded by losing their homes due to inability to keep up with mortgage payments: there is evidence that resulting higher stress levels have increased demand for social work support (Pemberton 2013). Some couples who want to separate cannot afford to do so, possibly contributing to recent rises in child protection referrals (Pemberton 2013). At the same time, cuts to services have seen a reduction of early intervention work, causing greater need further down the line (Hopwood and Pharaoh 2012). 
These authors surveyed eight English local authorities finding, for example, that one had seen a $70 \%$ increase in social work referrals in 18 months.

Although Scotland currently remains part of the UK, in 1998 'devolution' saw the establishment of a Scottish Parliament with responsibly for developing policy and legislation in a number of areas including social work and health services. While welfare benefits remain a reserved power of the UK government, there have been some attempts within Scotland to 'buffer' the impact of UK wide cuts. In 2010 the Christie Commission on Public Services in Scotland called for a 'radical change in the design and delivery of public services ... irrespective of the current economic challenges, to tackle the deep rooted social problems that persist in communities across the country' (p.viii). Its report highlighted the 'virtuous cycle' (p.6) the Commission would like to see between improving public service effectiveness while simultaneously nurturing stronger and better balanced economic development. However, it found that in reality services were often top down and unresponsive to individual needs and it estimated that $40 \%$ of public service expenditure could be avoided if a preventive approach was prioritised. At the same time, the Scottish Government's total budget was predicted to fall in real terms by over $11 \%$ between 2010-11 and 2014-15 (Christie, 2011), indicating that some reduction in public services was inevitable. A freeze on council tax rises over successive years has further reduced local authorities' income. The Government set up a £33 million Scottish Welfare Fund to help people in financial crisis and allocated a further $£ 5.4$ million to advice and support services to assist those most affected by cutbacks (Scottish Government, 2013). It is too early to comment on the effectiveness of these measures.

\section{What does this mean for families with disabled children?}

Cuts in welfare benefits and public services have most impact on the poorest in society (Wood, 2012). Disabled children are significantly more likely to grow up in poverty than non-disabled children (Shahtahmasebi et al., 2011). It has also been argued that the cuts affect disabled people, including those with severe impairments, disproportionately in comparison with the rest of the population because they tend to have lower incomes and higher living costs and many rely on both welfare benefits and public services. Recent research found that $81 \%$ of local authorities in England have set care eligibility thresholds at 'substantial/ critical only'; over half have closed a disability support service and 123 have increased charges to service users, some by up to $400 \%$ (Wood, 2012). A study funded by the Children's Commissioner in England explored the experiences of disabled children living in low income families, collecting the views of 78 children and 17 parents. It concluded that the impact of low income on ability to meet basic needs was often worsened by a poor standard of services, personal support and /or information.

The voluntary organisation Action for Children (2013) conducted a three-year study across the UK to examine the impact of government spending decisions on the 
children it works with, many of whom are disabled. They found that service infrastructures were fragmenting with a loss of early intervention work and a move towards dealing only with families in crisis. Of the 650 frontline managers involved in the study, $47 \%$ reported increased referrals, while $53 \%$ of services faced cuts in 2013 and $79 \%$ of staff contracts were due to finish by the end of the spending review period. At the same time, $83 \%$ of short breaks services for disabled children reported that demand had increased in the last year.

In 2012, Scotland's Commissioner for Children and Young People (SCCYP), who is appointed by the Scottish Government to promote and safeguard the rights of children and young people, commissioned a survey of local authorities to investigate whether, in their view, families with disabled children in Scotland were having difficulty accessing services due to changing eligibility criteria or assessment tools. The research found little evidence concerning the impact of the changed economic climate on services for disabled children, nor did the findings clearly point to tightening eligibility criteria or reduced levels of support (Lancaster, 2012). Rather, most local authorities reported that services for disabled children had thus far avoided the cuts. However, rising caseloads in most areas, along with no increase in budgets, implied an overall reduction of resource.

\section{Research Aims}

Following on from Lancaster's report, in 2013 SCCYP commissioned a second study (the subject of this paper) to examine changes in the availability and accessibility of publicly funded services for families with disabled children, this time from the perspectives of voluntary sector providers, disabled children, young people and their family carers. This paper focuses primarily on carers' perspectives, but where appropriate also draws on service provider data, in relation to the following research questions set out by the Commissioner's Office:

1. Have disabled children and young people and their families experienced any changes in the provision or quality of services over the last two years? If so, what sort of changes? Are they for better or worse?

2. For those who have experienced changes in the provision or the quality of services, have those changes affected children and young people and their families and, if so, in what ways?

3. To what do they attribute such changes? 


\section{Methods}

Ethical approval for the study was sought from the University of Strathclyde Ethics Committee and written informed consent was later obtained from all the participants.

The views of voluntary sector organisations, providing publicly funded services to disabled children and young people aged $0-18$ and/or their families, were gathered through an on-line survey. Four voluntary sector 'umbrella' organisations circulated the survey on our behalf. There were some overlaps in membership between these bodies but we estimated that about 300 voluntary sector organisations providing services to disabled children and their families were contacted; 53 responses meeting the study inclusion criteria were returned. 79\% (42 organisations) provided support to parents or advice and information: most agencies provided both. Almost all these providers also offered a range of other services, such as short breaks, leisure facilities, play schemes, educational support or support for self-advocacy. Twenty respondents said they catered for disabled children irrespective of impairment type, the remainder also catered for a range of needs, with only four having a specialised focus.

Ten focus groups were conducted with family carers across Scotland, recruited through voluntary sector organisations and, in one case, a local authority. The agencies were asked to use the following selection criteria: a mix of mothers and fathers, parents of children with a range of impairments, and some families known by the voluntary organisations to have experienced a change in services over the last two years. Between 2 and 12 participants attended each group with a total of 56 and an average of 5 per group. Two facilitators attended each group and carers were asked to respond to questions based on a semi-structured topic guide. (With participants' permission, the discussions were audio-recorded and transcribed

Five focus groups /group interviews were held with young disabled people aged 12$20^{i}$, again recruited through voluntary sector organisations. In all, 18 young people with a variety of physical, sensory and intellectual impairments took part, ranging from a joint interview with two participants to a focus group with five. These are not discussed here but the methods and findings are reported in Stalker et al (2013).

Analysis of the qualitative data was informed by the approach set out by Braun \& Clarke (2006) who identify six stages to thematic analysis: becoming familiar with the data, generating initial coding, searching for themes, reviewing themes, defining and naming themes and producing the report. Attention was paid to responses which differed from the norm to ensure the full range of views and experiences was reflected in the reported findings. Given the short timescale of the study, time did not allow for two researchers to analyse the same dataset. Instead, different team members took responsibility for analysing each data set and consulted on draft results with one or two colleagues who offered comments and critique. The lead 
author was then responsible for bringing the different sections together in the final report.

This study had a number of limitations. The organisations which recruited carers on our behalf were asked to invite at least some parents whom they knew to have experienced reduced support, thus possibly creating a biased sample: claims cannot be made for their 'representativeness'. In the fourteen weeks available for the study, there were limits to what we could control for and thus, caution should be exercised when extrapolating from the findings.

Secondly, this research did not canvass the views of staff in public bodies. The report can however be read alongside the Stage One research (Lancaster 2012) which did include local authorities' views.

\section{The sample of family carers}

In all, 56 people took part in the focus groups, 46 mothers, seven fathers , a foster carer (male), a grandmother and a grandfather (the child's parents also being present). Between them, they had 62 sons and daughters aged between 2 and 20 with a wide range of physical, sensory, intellectual and communication impairments. (Some carers had more than one child). Some children had life-limiting conditions and others were on the autistic spectrum. Focus groups achieved a good geographical spread across Scotland, from Inverness in the north to Dumfries in the south.

\section{Findings}

\section{Widespread reductions and withdrawal of services}

The majority of carers in every group reported changes in some aspect of the support which they or their child received during the last two years and in most cases, this was a reduction or, in some cases, withdrawal of services. This had occurred within a wide range of provision - social work, education, voluntary organisations, health and professions allied to medicine. For example, one local authority had closed all holiday play schemes for disabled children, while a number of families had seen their social work support withdrawn, carers being told that they no longer needed it. Similarly, when a staff member left post, s/he was not always replaced, resulting in a loss of service - this had happened in the case of social workers, sitting services and befrienders (the latter two services being provided by third sector organisations). More commonly, the level of support was reduced: thus the hours (or in some cases, days or even weeks) a child was allocated for short breaks, social clubs, play schemes or with a befriender had been decreased, as one father reported about a short breaks unit: 
I'm assuming it's because other people are not getting local authority short breaks from elsewhere, maybe due to cuts. There are a lot of new families: there is huge demand for [this unit] because the quality is so high.

Carers had seldom been consulted about reductions to their child's support and were often simply informed about it by letter or telephone: this included instances where a service was withdrawn. Only one parent reported that their child had been asked for his view about the support he would like. Some carers reported that, even when their child had been assessed as needing support, it was not always forthcoming. For example, one mother had been told her son would receive eight days of shortterm care during the Christmas holidays but he only got five hours. In several cases where young people had been assessed as needing one to one support, at school and /or social clubs, it was not provided, a situation described by a foster carer as 'setting the boy up to fail'. It had also been found that, where a 'new' service was offered to a family, an existing one was reduced or withdrawn, as this mother explained:

If [a child] has a pot of money, just say $£ 5000$...if they take in a new service which takes it up to $£ 8000$, they [social workers] either need to go with the begging bowl higher up the chain to get another $£ 3000$ or they need to cut what you already have in order to keep everybody up the stair happy, so it's easier for them to say to you, 'we're going to cut your service' than it is to go up the stair and say 'WE NEED an extra $£ 3000$ ' in order to have these two services [for this child]".

Also implicit in this account is a perceived failure of social workers to advocate on behalf of carers. However, other examples were given of social workers designing support packages, to meet assessed needs, which met carers' approval but were subsequently rejected or reduced by managers.

'Hidden' cuts were reported in several schools, due to higher numbers of pupils but no increase in staffing levels. One school, however, was facing a 3\% cut in its staffing budget from August 2013; carers wondered how this could be achieved without putting their children, who had severe complex needs, at risk:

We're getting little enough as it is.. In [my son's] classroom, there is only three of them [personal support assistants], and the services are getting worse and if they're going to cut the money, they're already over-stretched...

There were also reports of services trying to 'do things on the cheap' to save money. One example of this concerned a boy aged 14 with a life-limiting condition who used a wheelchair. An assessor in an NHS wheelchair and seating service was described as a 'jobsworth' by the boy's mother: "he had a form to fill in and had to tick all the boxes, saying 'your son can't really have this chair because it's going to cost a lot of money"'. When the family threatened to go to their MP and the press, the appropriate chair was provided. Three carers were of the view that a service provider had deliberately withheld information from them - about direct payments, short breaks 
and housing adaptations - in order to save money. This was echoed by a service provider who commented:

Social workers... misinform parent about direct payment saying 'you can only have one rate as a PA' as this is the cheaper rate rather than the agency rate.

Another aspect of changing policy and practice about which some carers were sceptical was inclusion, a finding reported in previous research eg: Dean (2003). Several lamented the closure of day centres which they had hoped their son or daughter would attend on leaving school: they resisted the idea of 'locality services' offering mainstream opportunities to young people, sometimes on a one- to-one basis. While describing themselves as not necessarily opposed to inclusion or independent living in principle, many carers considered this unsuitable for their son or daughter because they did not believe that other young people would make friends with him/her; several had experienced name-calling and other forms of lowlevel harassment in community settings. One mother had been told that her 16 year old son, who had 'challenging behaviour' and currently was assessed as requiring two-to-one support, would be quite capable of attending music classes at mainstream college on his own. Several carers felt that social workers had an unrealistic view of the young people's abilities - but also thought that inclusion was, again, sometimes promoted in order to reduce expenditure.

Similarly, there was a widespread view that direct payments and the introduction of self-directed support (implemented across Scotland in March 2014, although a few pilot schemes were in operation during our fieldwork period) was primarily a moneysaving exercise. Only four carers had direct payments/ self-directed support in place and held mixed views about them. While appreciating the choice and control it gave carers in arranging their child's support, there was a view that carers' unpaid labour, in terms of undertaking the associated organisation and administration, reaped financial savings for the local authority. One family, whose current short breaks allocation amounted to $£ 21,000$ per year, had been offered a direct payment of $£ 8000$ to purchase alternative provision.

Nine of the voluntary sector providers completing the survey had increased charges for their services. Carers in three areas reported that charging had been introduced for social or play activities. In one focus group, we were told that some children could not attend their usual holiday playscheme, run by a voluntary organisation but funded by a local authority, because their carers could not afford the fee of $£ 34$ per day (or £68 where a child required two-to-one support).

A small number of carers reported an increase in support. This was often as a result of an increase in their child's 'challenging behaviour', a deterioration in family circumstances (such as parents separating) or following intervention by a local or central government politician whom the carers had approached for help after experiencing long delays in securing support. 


\section{A shift from preventative work to crisis intervention}

Nineteen voluntary service providers (32\%) responding to the survey reported that local authorities had tightened eligibility criteria in the last two years, thus restricting access to voluntary sector services. A further $23 \%$ were aware of changes planned for next year. Several added that funding was now only available for 'complex' cases, defined in terms of a child's level of impairment and its impact on the family, or else where children were 'at risk' or a family at 'crisis point'. Certain children, including those with learning disabilities or with autism, were identified as 'not getting any help'.

This was reflected in carers' experiences of being turned away from services or being told they were coping adequately with little or no support. Several had requested social work support but had been told they could not have it, either because they 'did not need it' or because of staff shortages and cutbacks. Very few carers referred to eligibility criteria and it was not always clear whether or not a proper assessment or review of need had been carried out although some had been told they were 'a low priority'.

Carers often felt the decision that social work was not required was made too quickly, without investigating family circumstances properly. A mother, who had tried several times to secure social work support, reported:

On one occasion somebody got back to me; a lady came to visit me at home and we had a long chat about things and she said, 'that's all very unfortunate but because of the cuts there's not a lot we can do for you'.

In only one case was it reported that a local authority had broadened eligibility criteria for referral to the voluntary sector: this was for families whose social work support had been withdrawn. One mother commented that whereas in the past, in her authority, families with disabled children were offered short breaks (and indeed the original purpose of short breaks was seen in preventive terms), now they had to appear in front of a panel and 'fight' for the service. Another said:

It always comes down tae [to] money and it seems in a lot of situations that they only, if they do anything they only do it when somebody gets to crisis point.

A view shared by many was that social work focused almost wholly on families with child protection concerns, at the expense of those with disabled children, despite the latter's high support needs and stress levels. The opinion was expressed that, so long as they did not mistreat their disabled children, these families would get limited support, with one parent suggesting that if he threatened to assault his children, he would get more attention from his social worker. Another father admitted that he had come close to this on one occasion and described the social work response: 
At one point we rang up [a crisis team] and l'd lost it with [a nine year old boy] and l'd literally grabbed hold of him by the collar and just pushed him across the room and sat him down and I was shaking like a leaf and I rang social services and I said, look this is what I've just done to my, I've just grabbed him, you know pushed him down, and they said to me, 'I'll come round and I will speak to you in the morning' but the following morning they cancelled; it was three weeks later when a social worker turned up.

This incident indicates that even when families with disabled children are in crisis, they may not always receive a prompt response. Given that disabled children are three to four times more likely to be abused than their non-disabled peers (Jones et al., 2012), and despite the fact that most parents provide loving and secure homes for their disabled children, it is vital that social workers are aware of heightened risks and take prompt action when concerns arise.

\section{Unmet need}

Reductions in support to families with disabled children led to an increase in unmet need. Some of this was reflected in long waiting lists, highlighted by voluntary service providers and carers alike, for example for 'child in need' assessments, carers' assessments, direct payments, short breaks, sitting services, CAMHS teams, autism assessment and diagnosis, physiotherapy, occupational therapy, aids and equipment and home extensions. Some families waited between one and three years for such assessments or services.

However, voluntary sector providers also expressed concern about unrecorded need in relation to families whom they perceived as requiring support but who did not meet raised thresholds of eligibility and thus did not appear on waiting lists. A single parent under much stress due to her son's challenging behaviour only 'scored' 19 points for short breaks but needed 25 to qualify: she therefore received none. In some cases, the eligibility criteria were less clear: one mother had been told her 14 year-old son was 'too old' for short breaks while a third was informed, when her son's weekly sessions at a fitness class were stopped, that 'he'd had enough hours'. In several focus groups, carers highlighted the scale of unmet need:

We are a small group of people here that are representing a much larger problem; there is a much larger social problem here than just what's sitting in front of us...there are children out there that have got more serious disabilities that needs aren't being met either.

It was evident from survey and focus group responses that many families relied heavily on one provider or professional (usually within the voluntary sector but sometimes a local authority) for both practical and emotional support and would be badly hit should that be withdrawn, as this voluntary organisation noted:

With only a 9 month contract being given to us from the local authority, we could find that, come January 2014, [we] no longer provide the contracted 
service. This would mean many families who have a child with a disability would have no support at all. Many of our families only have [our service] and this only equates to 14 sessions per year.

\section{The impact of cutbacks on families}

Carers were keen to emphasise the benefits children and young people derived from attending social and recreational activities. As well as enjoying themselves and having fun, the young people mixed with their peers, made friends, gained confidence and social skills and had something to look forward to. When such activities were reduced or cut, children could be left, at best, disappointed and bored but sometimes 'low' and isolated. An after-school club in one area had been...

...one of the first things to go which was a shame as he loved spending time with his friends and his peers 'cause really you know when John's not at school, or the Bounty Club, he's quite isolated.

For young people on the autistic spectrum, holiday play schemes were also important in providing continued routine and structure outside school term time. In the authority which had stopped funding holiday play schemes, a parent commented:

I don't think people realise the impact it has on children like that. It's ok to say 'there's no money', but the reality is for us trying to get our children back into a routine after that, it's like hell.

A voluntary sector provider highlighted the wider long-term impact of the cutbacks:

Visually impaired children need habilitation training promoting personal independence from an early developmental stage if they are to be successful, confident adults who are economically independent and full members of Scottish society. We are failing them by not addressing this from infancy... Local authorities' stock answer is 'we have no money'. It is tragic.

As for the carers, where loss of support led to increased stress and feelings of not coping, some admitted they had lost confidence in their parenting capacities. Many expressed feelings of stress, anxiety and sometimes depression caused and /or exacerbated by reduced support and this was echoed by many of the voluntary providers completing the survey, one of whom commented:

Children and families are being let down in the current climate and as an organisation we have seen relationships break down completely and children have gone into the care system.

Cutbacks in support to the disabled child could also affect siblings, with carers less available to spend time with them: 
I found it was a good break not just for myself but for my other son as well... when we could go out and we could do things we couldn't normally do with David...or even just have a chill out day watching DVDs.

Many carers expressed anxiety about the future, both in terms of future cutbacks to public services which many expected and because several had been informed by social workers that their child's needs would decrease when s/he left school, a notion they did not accept. Some were also aware that, although they had short-term protection from welfare benefit cuts as a result of the UK government's decision to postpone certain changes affecting disabled children, this was set to change in the future. Parents of young people receiving Disability Living Allowance questioned the fairness of re-assessing their child's entitlement, given that the benefit was originally awarded 'for life'. A couple of young men had already had their DLA discontinued.

\section{Discussion and conclusions}

There are striking differences between the results of this research, which sought families' and voluntary sector providers' views about the availability and accessibility of public services, and those reported by Lancaster (2012) on the same topic but based on Scottish local authorities' perspectives. The two studies were conducted a year apart which probably accounts for some differences but both used surveys to elicit service providers' views, suggesting the difference is not methodological. This second study has found evidence of reductions in local authority budgets and services for disabled children, tightening eligibility criteria and support being removed without review or reassessment, contrary to the accounts of most local authorities in Lancaster's study. Decreased level and quality of services has led to less choice, long waiting lists and higher levels of unmet need. There has been a clear shift away from preventative work and early intervention, despite the Christie Commission (2011) highlighting these as a priority for public services in Scotland. Both carers and providers reported that families with disabled children were only helped when they reached crisis point, but the research also heard from families who appeared to be at 'tipping point' yet were not receiving the type or level of help needed. Making difficult choices about resource allocation is not, of course, a new challenge for public services and some changes to family support may have been linked to children's changing needs, new policy directions and competing demands from different user groups. However, these factors are being played out in the context of the austerity measures discussed earlier and carers themselves overwhelmingly attributed the changes they were experiencing to financial cutbacks. While it may be invidious to pick out certain groups of children as missing out more than others, it was noticeable that difficulty meeting the needs of children on the autistic spectrum was a recurring theme, along with reports of poor staff training in this regard and rising numbers of children being given this diagnosis (see also Weintraub 2011). 
The study findings point to a real danger that children and young people's entitlements under international conventions, UK and Scots law are being eroded, namely the UN Convention on the Rights of the Child (1989), the UN Convention on the Rights of Persons with Disabilities (2006), the Equality Act 2010, the Chronically Sick and Disabled Persons (Scotland) Act 1972 and the Children (Scotland) Act 1995. (Equivalent legislation to the last two Acts exists across the UK). The Children (Scotland) Act 1995 places a general duty on local authorities

to safeguard and promote the welfare of children in need in their area and, so far as is consistent with that duty, to promote the upbringing of children in need by their families by providing a range and level of services appropriate to the children's needs. (Scottish Office 1995; section 22(1)).

Disabled children are identified as 'children in need' and therefore local authorities have a range of statutory duties towards them.

In addition, under the Children (Scotland) Act 1995 (and the UNCRC), public bodies have a duty to consult disabled children about matters affecting them, using accessible methods, and to take their views into account: our findings suggest this is not happening. The Children (Scotland) Act 1995 requires authorities to seek parents' views as well. The same legislation places a duty on local authorities to formally assess a child's needs if parents ask them to do so. It was evident from what various carers said that this was not happening consistently. Under the Chronically Sick and Disabled Persons (Scotland) 1972, where a child is assessed as needing specific services such as aids and equipment, practical help in the home, assistance with travel or recreational facilities, and is eligible for them, then the local authority must provide them. Our findings suggest that some authorities may not be complying with this section of the Act: the duty may, on the other hand, help explain why eligibility criteria are being raised. A final legislative point worth stressing is that judicial review ${ }^{1}$ has shown that it can be unlawful to reduce or withdraw services from disabled children without prior reassessment or review of their needs. In several cases reported in this study, if a review had taken place, carers were not involved in or even aware of it, which clearly they should be.

The research suggests that some carers have a low sense of entitlement to services and that levels of trust in social work and other care staff are variable, with references to information and occasionally disinformation being given out. While a few carers spoke highly of their social worker, others perceived the latter as failing to advocate on their behalf. In addition, policy and practice developments seen as progressive by many practitioners, such as inclusion, independent living and selfdirected support, were less welcome to some carers, partly because such initiatives were seen as inappropriate for their son or and daughter and partly because they were perceived as primarily money-savers. It has been argued that certain key ideas

\footnotetext{
${ }^{1}$ See http://www.publications.parliament.uk/pa/ld199697//djudgmt//d970320/barry01.htm
} 
developed by the Disabled People's Movement, such as the social model of disability, 'independent living' and 'co-production', have been appropriated by governments developing polices which actually disadvantage disabled people. Morris (2011: p.12) comments:

Crucially the funding is lacking for the infrastructure of advice, support and advocacy required to enable people to truly exert control over resources (Beresford, 2009) and the emphasis is instead on personal budgets and direct payments as mechanisms for expanding the private market in social care, reducing the role of local authorities as providers.

It would be naive to hold social workers, or other front-line staff, wholly responsible for the undoubted shortcomings in services to disabled children and their families. Looking at the findings in the light of the austerity measures pursued by the UK government and the limited budgets available to Scottish local authorities, referred to in the introduction to this paper, it is evident that decisions made at higher levels are adversely impacting services to disabled children. In addition, the new managerialism within social work has resulted in reduced autonomy for front-line social workers and less time available for direct work with service users (Pemberton 2013): this was illustrated in our study by reports of social workers devising care packages which senior managers rejected, and the difficulty many carers experienced in contacting their social worker. However, recent years have seen a growing resistance on the part of some social work practitioners to those aspects of neoliberalism which threaten more social democratic principles and practices underlying the welfare state and intrinsic to the social work profession (Harlow et al., 2012). They have emphasised the importance of understanding the organisational, political and economic contexts in which social work is played out (Ferguson \& Woodward 2009).

\section{Policy and practice implications}

This section highlights key implications for policy and practice arising from the findings. These are presented in general, rather than Scotland-specific, terms.

Perhaps the most obvious lessons from the research are the need to ensure that public bodies consistently uphold disabled children's rights under legislation and international conventions, and the value of preventive work and early intervention. More effort should be made to consult young people about services, both on a oneto-one basis about individual support but also at a group level regarding wider service design and delivery. The views of children on the autistic spectrum and those from Black and minority ethnic communities should be included: this research identified particular difficulties meeting the needs of the former group, while the latter were conspicuous by their absence. 
Local and central governments have responsibilities to allocate sufficient funding to meet disabled children's needs and staffing levels should be adequate. Regular monitoring and active management of waiting lists would be helpful for both service providers and families. At a broader level, national inspection teams could consider investigating the level and quality of services to disabled children and their families with a view to issuing guidance to authorities.

Like many studies, the research findings about poor practice suggest a need for better focused staff training. This applies to staff at all levels and should include input on disability equality, disabled children's and their carers' legislative rights, communicating with disabled children and autism awareness.

Schemes promoting individual budgets, such as direct payments and self-directed support, were initially conceived as a way to give disabled people choices about and control over their support, facilitate use of mainstream facilities and promote inclusion. They should be used in that way and presented in those terms to carers and young people, highlighting the benefits of such schemes.. Support to help carers set up and administer the schemes should be available.

There is a need for many more social and recreational opportunities for young people: such schemes should be protected from cutbacks so far as possible. Under the Children (Scotland) Act 1995, disabled children's siblings are also 'children in need'. Authorities could usefully investigate demand for sibling support groups, the benefits of which have been highlighted elsewhere (Naylor \& Prescott, 2004).

Elder-Woodward (2013b) argues that society should take a broad view of the nature and purpose of services to disabled people (and other citizens), focusing on the value rather than the cost of care. The value is not just to the service user and their immediate family but to society at large, because when the right support is available, disabled people are able to participate and contribute to the common good socially and economically. This point was made by the voluntary sector provider, quoted earlier, who stated that society is failing disabled children if it does not support them to become 'successful, confident adults...economically independent and full members of Scottish society'. 


\section{References}

Action for Children. (2013). The Red Book 2013: Children under Pressure. http://www.actionforchildren.org.uk/media/7562887/red-book-2013.pdf. [Accessed 17 January 2014].

Stalker,K. MacDonald C., King C., McFaul F., Young C., Hawthorn M., Patrizio L. (2013). "It always comes down to money": recent changes in service provision to disabled children, young people and their families in Scotland. http://www.sccyp.org.uk/publications/disability [Accessed 5 August 2014].

Braun, V. and Clarke, V. (2006). Using thematic analysis in psychology. Qualitative Research in Psychology, 3, 2, pp 77-101.

Christie, C. (2011). Report on the Future Delivery of Public Services. Scottish Government. http://www.scotland.gov.uk/About/Review/publicservicescommission. [Accessed 17 January 2014].

Dean, J (2003). Disabled Young Adults and the Parental Home. York: Joseph Rowntree Foundationhttp://www.jrf.org.uk/sites/files/jrf/973.pdf. findings 973. [Accessed 3 March 2014].

Department of the Environment, Transport and the Regions (1998) Modernising Local Government http://www.local.odpm.gov.uk/bv/improvbv/improvbv.pdf [Accessed 6 March 2014].

Dezhao, C. (undated). The Decline of the US Economy: A historical comparison. Chinese Institute of International Studies. http://www.ciis.org.cn/english/201111/18/content 4635120.htm. [Accessed 4 March 2014].

Diamond, P. and Lodge, G. (2013). European Welfare States after the Crisis. London: Policy Network. http://www.policynetwork.net/publications detail.aspx?ID=4320. [Accessed 17 January 2014].

Duffy, S. (2013). A Fair Society? How the cuts target disabled people. London: The Centre for Welfare Reform. http://www.centreforwelfarereform.org/library/type/pdfs/afair-society1.html. [Accessed 17 January 2014].

Elder-Woodward, J. (2013a). A Consultation on the Future Use of Resources devolved following the UK Government's Decision to Close the Independent Living Fund. Personal response.

Elder-Woodward, J. (2013b). Independent living: the frontier of communitarian welfare? Disability \& Society, 28, 2, pp274-278.

Ferguson, I. and Woodward, R. (2009). Radical Social Work in Practice: Making a Difference. Bristol: Policy Press 
Fletcher, K. (2000). Best Value. in (ed.) M. Davies. The Blackwell Encyclopaedia of Social Work. Oxford: Blackwell.

Harlow, E., Berg, E., Barry, J. and Chandler J. (2012). Neoliberalism, managerialism and the reconfiguring of social work in Sweden and the United Kingdom.

Organisation, 20, 4, pp 534-550.

Hopwood, O. and Pharaoh, R. (2012). Families at the Frontline: Local spending on children's services in austerity. London: Family and Parenting Institute. http://www.familyandparenting.org/Resources/FPI/Documents/FPI_1715_Publication _WEB\%20pdf\%20(3).pdf. [accessed 3 March 2014]

Jones, L., Bellis, M.A., Wood, S., Hughes, K., McCoy, E., Eckley, L. et al. (2012). Prevalence and risk of violence against children with disabilities: a systematic review and meta-analysis of observational studies. The Lancet, 380, 9845, pp 899-907.

Lancaster, B. (2012). Social Work Services for Disabled Children and Young People and their Families: Assessment and eligibility. Edinburgh: Scotland's Commissioner for Children and Young People.

http://www.sccyp.org.uk/downloads/Adult\%20Reports/sh Elig Crit FINAL SCCYP REPORT 29 oct.pdf. [Accessed 17 January 2014].

Larkins, C., Thomas, N., Judd, D. and 16 other authors. "We Want to Help People See Things Our Way": A rights-based analysis of disabled children's experience living with low income. London: The Children's Commissioner for England. http://www.childrenscommissioner.gov.uk/content/publications/content 729. [Accessed 17 January 2014].

Morris, J. (2011). Rethinking Disability Policy. York: Joseph Rowntree Foundation. http://www.jrf.org.uk/publications/rethinking-disability-policy. [Accessed 17 January 2014].

Naylor, A. and Prescott, P (2004). Invisible children? The need for support groups for siblings of disabled children. British Journal of Special Education, 31, 4, pp199-206.

Pemberton, C. (2013) Community Care survey exposes how rising thresholds are leaving children in danger. Community Care. November 19.

http://www.communitycare.co.uk/2013/11/19/community-care-survey-exposes-risingthresholds-leaving-children-danger/. [Accessed 3 March 2013].

Rawls, J. (1970). Theories of Justice. Cambridge, MA: Oxford University Press. Scottish Government. (2013).Scottish Budget: Draft Budget 2014-15.

http://www.scotland.gov.uk/Publications/2013/09/9971. [Accessed 17 January 2014].

Scottish Office (1995)Scotland's Children:The Children (Scotland) Act 1995 Regulations and Guidance: Volume 1 Support and Protection for Children and Their 
Families. http://www.scotland.gov.uk/Publications/2004/10/20066/44707. [Accessed 3 March 2014].

Scottish Office (1998). Modernising Community Care: An action plan. Edinburgh: The Scottish Office

Shahtahmasebi, S., Emerson, E., Berridge, D. and Lancaster, G. (2011). Child disability and the dynamics of family poverty, hardship and financial strain: evidence from the UK. Journal of Social Policy, 40, 4, pp 653-673.

Taylor-Gooby, P. and Stoker, G. (2011). The coalition programme: A new vision for Britain or politics as usual? The Political Quarterly, 82, 1, pp4-14.

United Nations. (2006.) Convention on the Rights of Persons with Disabilities http://www.un.org/disabilities/default.asp?id=150. [Accessed 17 January 2014].

United Nations. (1989). Convention on the Rights of the Child http://www.unicef.org.uk/UNICEFs-Work/Our-mission/UN-Convention/. [Accessed 17 January 2014].

Weintraub. K. (2011). Autism Counts. Nature. 479: 22-24. 3 November.

Wood, C. (2012). Destination Unknown: Summer 2012. London: DEMOS. http://www.demos.co.uk/files/Destination Unknown Summer 2012 web.pdf?1340294386. [Accessed 17 January 2014].

\footnotetext{
'Voluntary agencies were asked to recruit 12-18 year olds for the focus groups but a few 19 and 20 years olds had been invited and turned up for the groups: it would have been insensitive to exclude them.
} 